\title{
Indicators on informal learning for active citizenship at school
}

\author{
Jaap Scheerens
}

Received: 14 January 2011 / Accepted: 24 March 2011 /

Published online: 12 April 2011

(C) The Author(s) 2011. This article is published with open access at Springerlink.com

\begin{abstract}
The article is based on an international comparative study in seven European countries, in which informal learning for active citizenship at school was explored by means of in depth case studies. Active citizenship is being recognized as an important goal of education and school pedagogy in an increasing number of countries. After defining the key terms "informal learning at school" and "active citizenship" the conceptual framework on which the study was based is introduced. Next, the most important outcomes of the study are summarized, in terms of core issues that showed varied implementation across countries. These issues are further analyzed in terms of context, input, process and outcome factors, with a strong emphasis on the process factors. Living up to school rules, student participation in school decision making, intercultural conflict and reflective pedagogy were identified as key "process" dimensions, impacting on informal learning for active citizenship at school. In a final section these areas are tentatively worked out as a set of process indicators, applicable in future international comparative studies.
\end{abstract}

Keywords Educational indicators · Citizenship education · Informal learning · School climate $\cdot$ Democracy at school

\section{Introduction}

This article is based on the results of an international comparative study facilitated by the European Commission. The study took place in seven countries, Cyprus, Denmark, England, Germany, Italy, Rumania and the Netherlands. The study was aimed at revealing the processes of informal learning at school for active citizenship. The overriding idea of the study was to see the school as a micro-cosmos of society, in which students are confronted with real life manifestations of the goals of active

J. Scheerens $(\bowtie)$

Faculty of Behavioural Sciences, Department of Educational Organization and Management, University of Twente, P.O. Box 217, 7500 AE Enschede, The Netherlands

e-mail: j.scheerens@gw.utwente.nl 
citizenship education. In this article specific attention is given to use the concepts explored in this study as a basis for the development of indicators on informal learning for active citizenship at school. As implied in the above, the general aims of the study were to clarify the core and related concepts of citizenship as a concern for schooling, and to study informal learning embedded in the school context in more detail. Consequently the state of the art of dealing with citizenship in schools in the participating countries was described on the basis of intensive case studies of a limited number of schools. The case study analyses dealt with the general issue of the "teach-ability" of citizenship at school, strengths and weaknesses of the context embedded and the explicit teaching approaches, the quality of methods and materials, and the possibility to asses the realization of citizenship at school by means of quantitative and qualitative assessment approaches. In the school analyses, school composition (the proportion of students with a minority background) was used as an important stratification variable.

\section{Basic concepts}

The goals of education for citizenship have been described as having three dimensions: a cognitive dimension with respect to knowledge about democratic institutions; a pragmatic dimension, in the sense of taking action and gaining experience; and an affective dimension, in terms of an attachment to the societies and communities to which one belong. Social and communication competencies are considered of central importance (cf. Ministerie van Onderwijs, Cultuur en Wetenschap 2004; Torney-Purta et al. 2001). In more recent contributions "civic competence" is further decomposed into an affective component (values, attitudes an intended behaviour) and a cognitive component (knowledge and skills), Hoskins et al. 2008, 18)

When it comes to methods in educating for citizenship at school, two broad categories were distinguished: firstly, approaches that see the school as a context to exercise "school citizenship" as a bridge to societal citizenship and state citizenship and secondly approaches in which school citizenship is characterized by specific goal directed teaching and learning activities.

From the perspective of teaching the first approach was described as "the context embedded approach", which was seen as fostering informal learning for active citizenship, while the second approach was referred to as the "explicit teaching approach", which is more associated with formal school learning directed at the goals of citizenship.

The key concepts used in the study, active citizenship, civic competences, and informal learning at school are summarized below.

Active citizenship has been defined as: "Participation in civic society, community and/or political life, characterized by mutual respect and non-violence and in accordance with human rights and democracy" (Hoskins 2006). Moral, legal, identity based, participatory and cosmopolitan facets of the citizenship construct can be discerned (Kennedy et al. 2008, 53). Some authors explicitly refer to "democratic multicultural citizenship" (Szelényi and Rhoads 2007, 27).

"Civic competence", as defined above (Hoskins et al. 2008) can be seen as the product of formal and informal learning for active citizenship. 
In order to define informal learning at school, it is relevant to consider the definitions of formal, informal, and non formal education. Formal education stand for the hierarchically structured, chronologically graded 'education system', running from primary school through university. Informal education is seen as the truly lifelong process whereby every individual acquires attitudes, values, skills, and knowledge from daily experience and the educative influences and resources in his or her environment - from family and neighbours, from work and play, from the market place, and from the library and the mass media. Non-formal education takes place outside the established formal system but is still intended to serve identifiable learning clienteles and learning objectives (c.f. Coombs and Ahmed 1974; Fordham 1993).

Specifications of the formal, informal and non-formal curriculum are also helpful in defining informal learning at school. The Council of Europe (2004, p. 38) mentions three categories within the non-formal curriculum: extra-curricular and extra mural activities (projects, visits, school exchanges, clubs, voluntary work, campaigns), school ethos (school climate, organizational culture, informal leadership, interethnic relationships) and school decision-making (school councils, children's parliaments, interest and pressure groups). Components of the informal curriculum are the hidden curriculum (peer learning, emotional encounters, leisure experiences) and learning from media (imitation of charismatic persons, influence of symbols, myths, metaphors, stereotypes, commercials).

In the study the focus was on informal learning in a formal setting. That is, informal learning within schools, where learning, apart from being stimulated by formal and explicit teaching, is seen as also taking place during the daily experiences inside and outside classrooms.

According to the embedded perspective on citizenship-oriented education, the values and norms of school life provide an exercise ground for important dimensions of civic behaviour that exist in the society at large. Three domains from which the values and norms of school life are generated are distinguished as (1) the institutional rules and norms of the school as an organization, (2) the leadership style of the school head, and (3) the school culture. Related concepts are the "hidden curriculum" and "school ethos". All these components can be seen as shaping the school's identity. The first is predominantly overt and formalized, related to McMeekin's (2003, p.3) concept of institutions at the micro level of organizational functioning. The second (leadership style) is exemplary with respect to more autocratic versus democratic governance and the third (culture) contains an additional facet of informal rules, norms and expectations (Maslowski et al. 2009, 5, Deal and Peterson (1999). Earlier research has shown that by experiencing a school culture where the exploration and expression of opinions are supported by teachers (e.g., controversial discussions, an open classroom climate) students form a positive attitude towards active citizenship and democratic values (Diedrich 2006). The term Ethos is used in the sense of the "feeling that results from the school culture" (Solvason 2005).

A final concept that was used in the study refers to a teaching approach in which teachers reflect on critical incidents in school life with an eye to their pedagogical potential for learning about citizenship, was indicated as "reflective teaching." 


\section{Conceptual framework}

The conceptual framework for this study consisted of three types of factors (see Fig. 1), citizenship competencies, to be seen as the outcome dimension, informal student activities and experiences at school, as the central process dimension and the school context.

The first factor, referring to citizenship competencies, can be seen as resulting from (among others) the informal student activities and learning experiences at school. The second factor, informal activities and experiences at school, represents situations in which students 'learn' certain citizenship competencies. As such, these can be considered as mediating factors between the competencies on the one hand, and the school context in which these activities and experiences are embedded on the

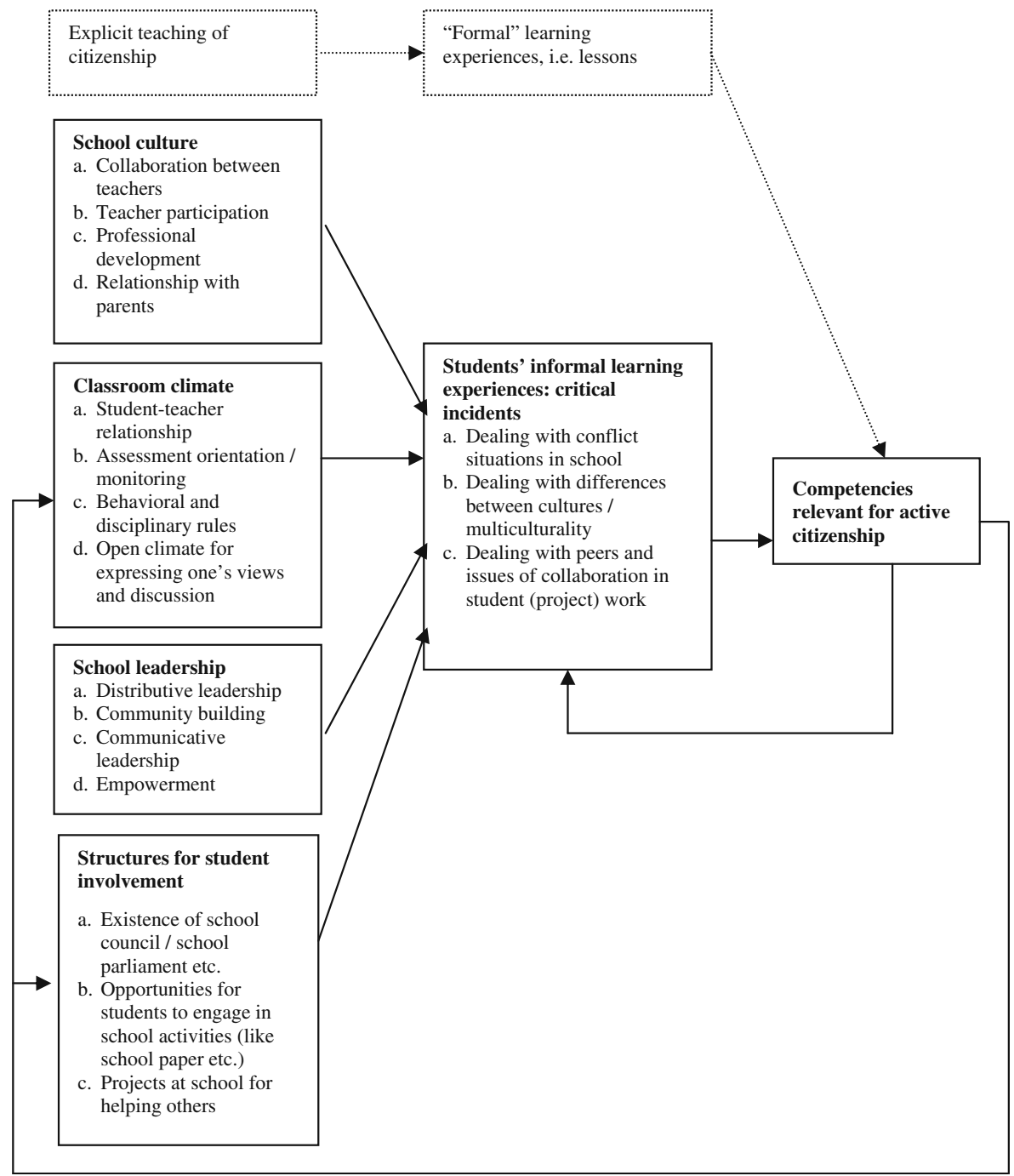

Fig. 1 Conceptual framework 
other. The school context can be conceived as consisting of factors stimulating or restraining informal student activities and experiences. Although citizenship competencies are considered as being influenced by students' informal learning experiences, it is acknowledged that these competencies, in their turn, influence informal activities and experiences. Moreover, citizenship competencies can also shape several school context conditions, under which the informal learning experiences take place. As such, the three types of factors are seen as related in a reciprocal rather than in a one-direction linear way.

\subsection{Citizenship competencies}

Since it was beyond the empirical part of the study to measure the outcomes of informal learning for active citizenship, reflections on the main components of citizenship competencies, made in the study's report, are not central to the main topic of this article. The interested reader is referred to Maslowski et al. 2009.

\subsection{Informal student activities and experiences}

Students' informal learning experiences will flow from students' self-reflection and dialogue and discourse in the classroom or in school. These processes and activities will be mainly triggered in an informal way by handling (potentially) conflicting situations. The informal learning that takes place is in first instance dependent on the reflective competencies of students (cf. Schön 1983). These, however, can be stimulated by others facing the same situation, like peers, or more likely the teacher. Informal learning of citizenship competencies, therefore, will occur as a result of self-reflection, dialogue and discourse. As a consequence, critical incidents where learning takes place are often unexpected or unforeseen situations in the classroom or in school, which give rise to any of these forms. These occur for instance, when conflict situations between students, or between a teacher and a student emerge. These informal learning experiences may also emerge from situations in schools where reactions are largely culturally bound, and where others react in a different manner to the same circumstances. And, they may arise from collaboration or mutual work with peers, for example during group work or other 'formal' classroom or school activities. So, more specifically three archetypical situations that could create critical incidents are discerned. Firstly, dealing with conflict situations in schools; this might concern conflicts between students and teachers, or between students. Secondly, dealing with differences between cultures and multi-culturality; culturally bound values may clash, or lead to surprises. Thirdly, the regulation and self organization during collaborative student work and peer interactions when taking part in the functioning of structural bodies within school.

\subsection{The school context}

Research studies focusing on school and context factors that influence the (informal) learning of citizenship competencies, or that might enhance or hinder situations in which citizenship learning occurs, are relatively sparse. Notable exceptions are studies described in the recent reviews of Deakin Crick et al. 
(2004), and Halstead and Taylor (2000) on this issue as well as recent reports by the Council of Europe (2004) and Hoskins et al. (2008). Largely based on these reviews, as well as a few studies which addressed this topic recently, the following factors were identified: classroom climate, school culture, school leadership and structures for student involvement.

Aspects of classroom climate and school culture that are considered particularly relevant for citizenship values are the way conflicts are dealt with, shared values among students and teachers, cooperative decision-making, issues of trust and the establishment of clear behavioral rules. With respect to leadership, the issue of autocratic versus democratic decision-making is particularly relevant. As far as structures for student involvement are concerned previous research, especially in the United States, has indicated that student participation in decision-making at school may contribute to the democratic awareness, skills and attitudes of student in schools, as well as society. Taylor (2002) studied the role of school councils and their contribution to citizenship education in the UK. Her study suggested that participation of students in school councils can make a positive contribution to the students' personal development, to their social interaction and to their sense of active engagement. According to teachers, the major benefits for student councilors are their increased skills of communication, especially speaking and discussion, their experience of meetings, their 'political grounding' and their willingness to take responsibility for action. Students who participated in school councils also report that they are more aware of and have developed an understanding of democratic procedures and practices. This encompassed, among other things, learning to ask other people's views, being a representative, arguing a point of view, and being accountable for decisions taken.

The complete conceptual framework for this study is schematically presented in Fig. 1.

\section{Method}

\subsection{General approach}

The object of this study is quite complex. Approaching it in an international comparative context added to this complexity. Given the state of the art of research in this field, and given also the limited scope of the study, the ambitions had to be limited to an exploratory approach. The conceptual framework was developed to focus the data collection, in order to enable comparable descriptions. Given the exploratory nature of the study and the limited scope in terms of time and resources a qualitative cases study approach was chosen as the overall data collection strategy.

What the case studies were expected to yield was, first of all, a richly documented description of the school context of 6 schools in each of the participating counties, describing culture, classroom climate, leadership style and structures for student involvement, allowing for conclusions about the quality of school contexts as stimulants of informal learning about citizenship. Secondly, the study was expected to generate a set of examples of situations and critical incidents that showed potential for informal learning for citizenship, yielding conclusions about the potential of this kind of learning, and also offering suggestions on how schools might further exploit this kind of learning opportunities. 
The case study approach was prepared by means of a try out phase in three countries, Denmark, Italy and Germany.

\subsection{Selection of schools}

Countries were invited to select 6 lower secondary (ISCED level 2) schools, which included Grades 8 to Grade 9. Since school composition in terms of the percentage of minority students per school was seen as particularly relevant to the issues addressed in the study, countries were asked to select two schools with less than $20 \%$ minority students, and four schools with more than $20 \%$ minority students. In addition it was suggested to diversify this latter category of four schools further, and to choose schools with medium and high percentages of minority students.

No further stratification factors were proposed, although countries were free to increase variability between schools by differentiating between schools in urban and rural areas and large (in terms of number of enrolments) and small schools.

\subsection{Data collection}

The data collection in the case study schools was guided by a short questionnaire to describe the school context and an elaborate checklist to be used as a basis for interviews and focus groups, involving principals, teachers and students. The checklist is to be seen as an operationalized version of the conceptual framework, presented in the previous section.

The main data collection categories were matched with the main data-providers, school head, teachers and students, as indicated in the table below. In the "other category" could belong: non teaching staff, aspects of school life as observed during school visits and documentary analysis. In the table no distinction is made between individual interviews and focus group sessions, with respect to teachers and students.

\begin{tabular}{lllll}
\hline & School director & teachers & students & other \\
School background characteristics & $\mathrm{X}$ & & & $\mathrm{X}$ \\
Explicit teaching of citizenship & $\mathrm{X}$ & & & $\mathrm{X}$ \\
School culture & $\mathrm{X}$ & $\mathrm{X}$ & $\mathrm{X}$ & $\mathrm{X}$ \\
Classroom climate & & $\mathrm{X}$ & $\mathrm{X}$ & \\
School leadership & $\mathrm{X}$ & $\mathrm{X}$ & $\mathrm{X}$ & \\
Structures for Student involvement & $\mathrm{X}$ & $\mathrm{X}$ & $\mathrm{X}$ & $\mathrm{X}$ \\
Student's informal learning experiences & & $\mathrm{X}$ & $\mathrm{X}$ & $\mathrm{X}$ \\
Informal inventory of learning outcomes & & & $\mathrm{X}$ & \\
\hline
\end{tabular}

Respondents were selected by the research teams in correspondence with the school principals.

Researchers monitored whether teachers and students were selected within certain broad strands (e.g. students in the age range of 14 and 15 years) and in a way that diversity was guaranteed among the responding students and teachers. For example, 
with respect to teachers teaching basic subjects or subjects related to citizenship education was to be included, and students needed to be equally divided with respect to gender and belonging to a cultural minority group. Within these general guidelines selection and self selection of respondents was initially worked out by the school principals and checked by the researchers.

The data were collected by the national research teams, which consisted of academically trained researchers, operating in pairs in order to support the reliability of the data collection. The school context questionnaire and the check-lists representing the conceptual framework are presented in the Annex to this paper.

\subsection{Aggregation of information and reporting}

Countries were invited to produce school descriptions that followed the categories of the operationalized framework, described in the Annex to this paper, using them as section headings. In addition countries were advised to keep and put on record more extensive recordings and elaborate protocols as background documentation. Next, countries were asked to provide summary reports (in English) about the 6 schools in their country (maximum length 15-20 pages). The country reports were to follow the sequence of categories from the operationalized conceptual framework, and report the dominant patterns observed in the six schools, as well as important differences that were observed between the schools, the language should be descriptive narrative and include occasional striking examples. Apart from the systematic description, countries were asked to write a section in which conclusions are drawn, main findings are recaptured and a connection is made with relevant aspects of the national educational context. These summary reports were integrally included in the project's report (Scheerens, 2009 ed.), with contributions from Pashiardis et al. (2009), Moos et al. (2009), Thomas et al. (2009), Abs et al. (2009), Barzanò et al. (2009), Paunescu and Alexandrescu (2009) and Hendriks and Scheerens (2009).

\section{General outcomes of the study}

The study was designed as an exploratory internationally comparative study, which meant that the conceptual framework, which guided the empirical data collection, should be seen as descriptive rather than analytic, in the sense that differences between countries could be predicted from it. The main conclusions of the study regarded the heuristic usefulness of the descriptive conceptual framework and stated that this heuristic usefulness was affirmed, in the sense that the framework served in laying bare relevant dimensions of informal learning of active citizenship at school and showing relevant communalities and differences between countries. A first attempt at explaining differences across countries, post hoc, was done by considering the power distance dimension from Hofstede's classification of national cultures (Hofstede, 1991). As this article focuses on the descriptive contents of the conceptual framework and in operationalizing it in the form of indicators, no further attention will be given to this kind of analytic interpretation of the results (see Scheerens, 2009, chapter 12). 


\section{More detailed descriptive results and general implications for identifying indicators}

Results are presented under the headings of the national context, the school context and critical incidents of informal learning for active citizenship. It should be noted that the presentation is exemplary rather than representative for the results on each country.

\subsection{The national context of citizenship education in the seven countries}

\subsubsection{Curriculum aims and structures}

Citizenship is a separate subject in four countries, Cyprus, England, Romania and Germany. In all other countries the cross-curricular form predominates, with social studies and history as the most frequently mentioned core subjects. Interestingly, Cyprus, England and Germany are also among the four countries that explicitly mention citizenship in the sense of learning from school life, the "embedded" view on citizenship education that stands quite central in this study. The fourth country that explicitly refers to this is Denmark.

\subsubsection{Extra curricular activities that offer opportunities for student participation}

In practically all of the participating countries students have the opportunity to take part in student, class or school councils, and sometimes even to take part in national level decision-making bodies, such as a school Parliament. In Denmark the influence of students seems to be quite significant, because students even have a voice in the planning of teaching by the teachers. In Danish schools a formally recognized part of the timetable, known as Class Time, is dedicated to discussing pertinent social or disciplinary issues. A remarkable example from the German country report is the one of students developing a kind of disciplinary contract, as part of a school development project in Berlin. In Romania there is a democratic elected National Council of Students that is recognized by the Ministry of Education as consultative body. In Italian schools a student statute specifies the rights and duties of students at schools.

Finally, all kind of special activities that students can plan and organize in schools, like the preparation of a school journal, a theatre club, a school band etc. were occasionally mentioned by the countries as well.

\subsubsection{Teachers' preparedness and professional support for citizenship education}

What stands out is the elaborate infrastructure that exists in Germany in the field of training and support for political/civic education as a school subject; nevertheless more than $50 \%$ of the lessons in political/civic education are given by teachers, who have no academic training in that field. England has an elaborate set of training and support facilities in this field, as well, but this is of more recent origin than is the case in Germany. The conditions regarding teacher training and support in Denmark underline, once more, that in this country the relatively new emphasis on citizenship 
education is strongly embedded in the existing overriding orientation to democracy in Danish education. In the other countries initial training, in service training and support are more recently developed and appear to be more modest than in the three earlier mentioned countries.

\subsubsection{Current debates and controversial issues}

In three countries the debate on citizenship appears to be at least partly overwhelmed by the problems that schools experience with the integration of cultural minorities. This issue seems to dominate the debate in the Netherlands, Denmark and Germany. According to the country description on England, the debate in this country appears to be of a more technical nature: how to give education of citizenship, as a formal part of the curriculum a less marginal position, how to integrate it with more embedded experiential leaning models, and how to assess it. Finally, apart from the issue of multi-culturalism, the debate in Germany is also about fundamental perspectives on the content of citizenship education, with on the one hand a more knowledge oriented outlook on societal and political institutions, and on the other hand a more personalized emphasis of particular dispositions, emotions and value positions.

With an eye to select areas for indicator development, these results about national contexts focus the attention on the curricular position of citizenship education, as a separate subject or a topic that is to be addressed throughout the curriculum. Next it would be interesting to try and capture something about the history of citizenship education in a country, for instance by analyzing whether, and since when, citizenship is part of the syllabus of teacher training. Finally, the example of Denmark draws the attention to having an indication of the degree to which democracy is a central value in school pedagogy in a country, although it is notoriously difficult to develop comparative indicators on educational goals.

\subsection{The school context}

\subsubsection{Aspects of the school culture and the institutional norms of the school}

The main assumption among countries appeared to be that a cooperative atmosphere and a democratic, participative approach would function as a favorable context for informal learning of the students about aspects of citizenship. Actual practice among countries differed, according to tradition and specific circumstances. In Denmark, for example, the aims of the Folkeskole are very much oriented to democratic values. All case study schools in Denmark emphasized a good collaborative atmosphere at school. Most schools had an array of traditions and events that contribute to forging a sense of community and belonging at the school. In England, the overall view, shared by staff and pupils, was that teachers mostly work together. Noticeably, pupils observed that the collaboration between teachers can vary between subjects. In terms of the clarity of school regulations and respect for collective norms, across the six case study schools in England, rules were generally agreed to be clear and most students follow the regulations. As far as school culture, seen in terms of the level of trust between parents, teachers and pupils was concerned, there was quite 
high variation of pupils' responses to trusting teachers between schools, ranging from $100 \%$ to $17 \%$. On the issue of trust, the Rumanian case study report concluded that only $10 \%$ of the investigated students said they trusted in their teachers to confess and to be advised on personal matters, while $60 \%$ of the students said they did not have the courage to ask questions to the teachers, in many cases even if they were questions related to the taught subject. Aspects of the school culture that were highlighted in the German case study reports were: the issue of grading, which was seen as a pivotal area of student engagement, having strong connotations of being treated fairly.

\subsubsection{Dealing with diversity and coping with rules}

The German case study report, like the reports from Cyprus and Italy, refer to the importance of good school community relationships, and some difficulties to engage parents from cultural minority students. The Dutch case study put much emphasis on rules and regulations. Secondary schools in the Netherlands are obliged to draw up a student statute. The student statute arranges the rights and duties of pupils. Schools are free to determine the content.

\subsubsection{Classroom climate}

The case study descriptions on classroom climate are quite dominated by the issue of minority students in classrooms. In Cyprus certain difficulties to relate to foreign students, due to language problems, are dissonant in an overall friendly atmosphere in classrooms. In the Danish case study schools issues of diversity seemed to be discussed much more intensely at schools with many minority students. "At a school with only few minority students the students claim that teachers rarely take initiatives to debating exciting issues. They have spent some time in Danish and Civics to debate issues about immigrants, senior citizens and so forth. But the issue about the Mohammed drawings in a Danish newspaper has not been debated at all" (Moos et al., 2009) The English case study reports states: "With regard to how schools deal with understanding and respecting issues of diversity and the rights of minority groups, it seemed that to some extent this was a key feature of the case study schools where there is a relatively high proportion of minority groups either in terms of ethnicity or disability (or both). Although, in the two case study schools where there was a lower percentage of minority groups, staff seemed to be aware of this issue and in some cases provide convincing evidence of successful strategies to address this issue". Interestingly a school with small percentages of cultural minority students expressed this as a problem, because it created an insufficient context to illustrate diversity" (Thomas et al., 2009). In the Netherlands in most of the schools the teacher-pupil relationship were characterized as 'authoritative'. This means that teachers set rules and standards and then try to create compliant behavior through dialogue. Teachers don't judge themselves as democratic. Other aspects of classroom climate that stood out in the case studies were discrepancies in the role of teachers, who formally are expected to function as authorities where pupils might need a more caring attitude (Italy and Rumania), reflection on social aspects of cooperative learning (England) and instances of reflection on social issues (Germany). 


\subsubsection{School leadership}

Across and within countries divergence was observed in the degree to which head teachers were either formal authorities or initiators of participative decision making within schools. Denmark shows the clearest image of participative, democratic leadership at school. The English case study report concluded that head teachers were perceived as autocratic rather than democratic. Much divergence in leadership style was observed among the German case study schools. Rumanian school heads were described at hierarchical leaders. In Italy too, the school leaders have a distinct hierarchical position, although there are democratic mechanisms, namely the college of teachers, active as well. In the Netherlands leadership style has become more formal hierarchical an strict, as a consequence of scale enlargement and the feeling that stricter discipline is required in the face of serious disciplinary issues in schools with large percentages of minority students.

\subsubsection{Structures for student involvement}

The way such structures are embedded in the national educational context was already summarized in an earlier section. In addition, countries have provided additional information on the functioning of these structures. In the case of Denmark these structures seem to generally function well, as they can be seen as one of the manifestations of the overall orientation of education towards democracy. In the case study reports of England and Germany, some critical comments on the functioning of school councils etc. was made in the sense of doubts about the real influence (England) and the existence of student counter cultures, where students active in councils were seen as being in the camp of the teachers. In addition, a broad range of special activities and extra curricular activities are sketched in the various country reports. In Cyprus, for example, students' conferences at local and national level, environmental projects, sport activities and championships, theatre plays, school newspaper publications, policestudents collaboration pilot programs, participation in film competitions for the environment, and "car wash day", were mentioned as examples

An a priori category contained in the conceptual framework was activities aimed at helping groups outside the school, like voluntary work. This category was hardly addressed in the case studies.

The predominance of the multi culture issue marks school and perhaps also classroom composition as a relevant indicator category. Next, hierarchical or more participatory, democratic leadership is an important area, as is the predominance and clarity of school rules and the way these are maintained. Other relevant areas for indicator development that are underlined by the case study results are opportunities for students to function in democratic organs of the school and a series of teacher orchestrated pedagogical instances related to cooperation, evaluation and discipline.

\subsection{Categories of critical incidents that illustrate informal learning for active citizenship}

The critical incidents are meant to illustrate school and classroom events that have high potential of significance to illustrate aspects of citizenship, in terms of "civil behavior at school". Informal learning from such events could take shape in simply 
being involved in the situation in question, or, in addition to this, result from reflective reactions to it, by teachers, students and principals.

In the case of Cyprus all critical events were related to the issue of the influx of foreign students. The critical incidents described issues of conflict, perceived unfair treatment and attempts to achieve integration by the schools. One event illustrated the active attempts of a school to make dealing with a conflict into a pedagogical experience.

In the Danish case study the difference between three types of schools, depending on the school composition, were highlighted. As in the case of Cyprus, schools with a relatively high percentage of minority students were challenged and inspired most to actively deal with citizenship relevant reflections: "We see different ways of handling values, norms and regulations: In schools with very few immigrantsplaced in rather affluent areas, norms seem to be based on traditions and the professionals in schools feel no need for much discussion. In schools with a medium percentage of immigrants we see cultural clashes emerging: Teachers and leaders seem not to be fully aware of what kind of problems and discussions are needed when schools become more multicultural. The situation is distinctively different in schools with many immigrants. The discussions and negotiations of rules and norms are an important part of every day life in these schools. Those schools are also placed in challenging socio-economic circumstances where differences between the mainstream Danish citizen and socially marginalized groups is an obvious aspect of life for students and schools. It seems that those schools are developing modes of understanding and practices that are more able to prepare young people for citizenship in a multicultural society" (Moos et al., 2009)

The English case study centered critical incidents on a number of themes:

Clarity and (in) consistency of school rules

The researchers noted that informal learning opportunities arose particularly from situations were rules were applied in an inconsistent way.

Pupils' involvement in decision-making

It was noted that student influence mostly related to relatively minor issues, and that progress could be made by involving students in more involving development of community support.

Teachers being perceived as role models

Only in relatively few cases were teachers seen as outstanding role models, in most other instances they were seen as "good enough" role models.

Proactive policy of schools to enhance parental involvement

In the case of one school, where parental involvement was experienced as particularly problematic, much was invested in the involvement of parents from minority ethnic communities.

Inclusive education

This seemed to pay of in building respect and support for disabled students. 
New educators' roles

The role of learning mentors, teaching assistants, technicians, a school nurse, police officer linked to the school, and especially peer mentors as being important in providing opportunities for informal citizenship learning.

The school as formal hierarchy

With respect to the issue of the school as a hierarchy, the question was raised to what extent schools could ultimately provide sufficient informal learning opportunities without compromising their hierarchical position.

The status of citizenship education

A low status of citizenship education was noted in the English schools.

The German case study report sketched the following types of situations in which relevant critical incidents occurred: attitudes of staff in terms of being optimistic or pessimistic about the capacity of students to function well in democratic school procedures; the observation that students appeared to have more trust in their teachers than in their peers; conflicts and inconsistencies in the application of regulations between principals and teachers on the one hand, and teachers and students on the other; differentiation between rules that are to be strictly applied in all circumstances on "big issues", such as violence, and rules for which there is room for negotiation as they deal with relatively minor issues; e.g. the use of an mp3 player; illustration of the positive effect of transparency in grading in one school, and negative influence of non transparency in the sense that, in another school, these were seen as a measure to protect the authority position of teachers. A specific potential was seen for staff members from minority groups, as they may also play a particular intermediary role with respect to parents from minority group students.

As in other countries the case study report of Italy noted that the most interesting experiences emerged from the management of the relationships with foreign students and their parents. Many examples were given that illustrate that dialogue, listening and information provision can positively resolve difficult issues. The function of auxiliary staff, care takers, etc. was highlighted, as they are very prominent in Italian schools:

In The Netherlands critical incidents mainly referred to dealing with diversity (both with regard to ethnic and socio-economic background), and coping with rules and conflicts. In addition, some examples were reported on building a school community and pupils having a say. Also, many (formal and) informal learning situations were reported in which teachers tried to exert influence the opinions, attitudes, and behavior of the pupils (and indirectly also their parents). These critical incidents often arose from either a topical subject or a conflict situation, and were most evident in the schools with a mixed population or the school with many minority students.

In contrast to the other countries the schools in Rumania did not consider the issue of minority students a serious problem, nor as a positive condition for experiences regarding informal learning of citizenship. In the student interviews students mentioned the following sources of informal learning: rituals and ceremonies (school openings/religious service), school festivals (school year opening/8th of March/1st of June), display of class regulations, camps, participation to festivities related to religious holidays, periodical meetings with the representatives of 
the national minorities, school attendance parties, participation in different kinds of extra-school activities (artistic, sportive, ecological, religious).

Despite the somewhat divergent position of Rumania, the summary of categories of critical incidents generally underlined the importance of the issue of cultural minorities in the school. Interestingly, schools across countries tended to deal with these as challenges and opportunities, while, at the same time, it was clear that the schools were sometimes confronted with huge problems.

The issues that the description of classroom level critical instances yields for indicator development mirror to some extent the areas that were already identified at the level of the school context. The difference being that here the focus is on the experience of students. Learning from cultural diversity clashes, dealing with conflict and living up to school rules are some cases in point.

\section{Towards indicators on informal learning for active citizenship at school}

The conceptual framework that was developed for this study, and which was rendered once more at the beginning of this article, generally fulfilled its function, as a focus for the data collection, i.e. by structuring the case study descriptions. When it comes to developing indicators, the main categories of the conceptual framework could be taken as a basic framework. In our study the outcome dimension was left untouched, which means that the core of the indicators would be about the school context and specific situations at school that are seen as fostering informal learning for active citizenship. Next, some basic characteristics of the regulation of citizenship education in a country might be developed into system level indicators.

Indicators are seen as relatively simple quantitative measures of core aspects of the phenomenon in question, in our case education, which allow for an evaluative judgment. Indicators are usually categorized according to a context- inputprocess- outcome categorization. When it comes to drawing evaluative conclusions from indicators, outcome indicators are the most straightforward category. Highest scores on measurements of citizenship competencies would be the most valued. Context indicators are often used to further qualify or differentiate the evaluations on outcome indicators. Input and process indicators can either be used as policy relevant explanatory conditions of high or low outcomes, or be judged "on their own" in the sense of intrinsically good, or as instances of what is considered good practice.

In our case, given the focus of the study, the results lent themselves to generating ideas on relevant context, input and process or throughput indicators concerning informal learning of citizenship related competencies at school level. To some extent system level context indicators are addressed as well, while the study has not led to empirical testing of outcomes of informal learning for active citizenship. Because of the need to be concise and quantitative in the construction of indicators, the complex material from the qualitative case studies is to be translated in a set of relatively simple and straightforward questions. What follows are mainly basic structures for questionnaire items, like the ones that are used in international assessment studies like the IEA Civic Education Study. 


\subsection{Indicators concerning the context of the school}

The percentage of cultural minority students at school appeared to be a most relevant feature for the intensity to which citizenship relevant experiences were dealt with at school. In addition, it might be interesting to have information on the number of teachers with a minority background, as well as on the composition of school boards, more particularly whether representatives form minorities are part of such boards.

\subsection{Indicators on leadership style and school decision making}

Autocratic versus democratic leadership determines the kind of authority situations students are confronted with at school. The core issue seems to be participative decision making, meaning the degree to which teachers have a say in important school matters. An indicator measuring participative decision-making could be constructed in such a way that the decision-making structure of the school would be revealed as well. This could be accomplished by crossing decision-making agencies with categories of decisions, as is done in the school background questionnaire of the OECD PISA study (e.g. OECD 2007).

\subsection{Indicators on school culture and classroom climate}

Variables that appeared to be relevant from the country case-studies were: a collaborative atmosphere as far as between teacher relationships are concerned, aspects of a disciplinary climate, such as the presence or absence of clear behavioral rules, the degree to which rules are actually lived up to and monitored, how conflicts are dealt with, the experienced fairness of grading and marking and opportunities for cooperative learning. Such variables could be operationalized as structured questionnaire items, where school heads, teachers and students are asked to indicate whether certain incidences of these variables occurred, and whether they were experienced as facilitating or constraining learning and well-being.

7.4 Indicators on specific opportunities to function in democratic organs of the school

To some degree this area overlaps with the one on leadership and school decisionmaking, the relevant question being to what extent the school offers opportunities for student to participate in decision-making bodies of the school. Related questions could be asked for functions that deal with the classroom organization or even the participation in the planning of teaching priorities. Also specific bodies that are created to organize student voice, like a school parliament could be included in these questions. The overall design of such questions could simply be: does your school offer opportunities to participate in: the planning of lessons, the planning of extra curricular activities, the school parliament (yes/no, or does not apply).

\subsection{Indicators on critical incidents of learning for active citizenship}

Structured questions could be asked about "how often does the following occur during your classes". In order to do so, situations could be described like: 
discussing the fairness of marks received, discussing the justification of the school rules, talking about conflicts between students and teachers openly, discussing issues of right and wrong, discussing different cultural values, talking about fairness in judging the results of group tasks, talking about political issues, discussing democracy and applications of democracy, discussing basic human rights, carrying on a debate about freedom of speech and discussing the exemplary function of the school as a democratic organization.

\subsection{System level indicators on the position of citizenship education}

As our study showed, important differences exist between countries with respect to the way citizenship education is part of the formal curriculum as a specific subject, is mentioned as a substantive part of several other subjects, like history, social sciences, or is not mentioned at all in the formal curriculum. Similarly countries differ in the degree to which citizenship is part of official teacher training programs, and in the degree to which citizenship is part of examinations of formal assessments.

The set of rudimentary indicators is schematically summarized in Table 1 .

School level process indicators on fostering informal learning for active citizenship could be applied in international comparative assessment studies, in check-lists for school inspection, and points of attention for school self-evaluation. In all these applications specifying the issues in terms of indicators has the advantage of allowing for a more data driven approach in the further development of citizenship education. Ideally this would apply that the complex and fuzzy reality of informal school learning becomes more manageable. At the same time the complexity of the issue would keep requiring qualitative, more in depth description, as was tried in our study, as well.

Table 1 Topics for indicators on informal learning for active citizenship at school

\begin{tabular}{|c|c|c|}
\hline System level indicators & School context indicators & $\begin{array}{l}\text { Critical incidents of learning } \\
\text { for active citizenship }\end{array}$ \\
\hline Citizenship in the curriculum & $\begin{array}{l}\text { Percentage of cultural minority } \\
\text { students per school }\end{array}$ & $\begin{array}{l}\text { Learning from cultural } \\
\text { diversity clashes }\end{array}$ \\
\hline $\begin{array}{l}\text { Citizenship part of teacher } \\
\text { training }\end{array}$ & Leadership style and decision making & $\begin{array}{l}\text { Questioning the democratic } \\
\text { level of the school's governance }\end{array}$ \\
\hline \multirow[t]{6}{*}{$\begin{array}{l}\text { Citizenship formally } \\
\text { examined }\end{array}$} & $\begin{array}{l}\text { Opportunities to function in the } \\
\text { democratic organs of the school }\end{array}$ & Living up to school rules \\
\hline & $\begin{array}{l}\text { School culture and climate } \\
\text { (atmosphere, cooperation, } \\
\text { disciplinary climate, fairness of } \\
\text { marking, cooperative learning) }\end{array}$ & $\begin{array}{l}\text { Incidents in which values } \\
\text { and human rights are at stake }\end{array}$ \\
\hline & & Fairness in marking \\
\hline & & Openly discussing conflicts \\
\hline & & Dealing with conflict \\
\hline & & Discussing actual political issues \\
\hline
\end{tabular}


Open Access This article is distributed under the terms of the Creative Commons Attribution Noncommercial License which permits any noncommercial use, distribution, and reproduction in any medium, provided the original author(s) and source are credited.

\section{Annex}

- OPERATIONALIZED CONCEPTUAL FRAMEWORK; CHECK-POINTS FOR DATA

\section{A. SCHOOL BACKGROUND QUESTIONNAIRE}

1) Is the school:
a) a combination of a primary and secondary school
b) a lower secondary school
c) a combination of a lower and upper secondary school

2) How many students are enrolled in the school?..........

3) Is the school located in
a) a village: less than 5,000 inhabitants
b) a small town: 5,000-20,000 inhabitants
c) a medium sized town: 20,000-100,000 inhabitants
d) a big town: 100,000-500,000 inhabitants
e) a metropolis: more than 500,000 inhabitants

4) What percentage of minority students are enrolled in the school?........\%

\section{B. EXPLICIT TEACHING OF CITIZENSHIP}

Are the students in grade 8 and 9

a) taught citizenship as a specific subject, period on the timetable

b) taught cognitive aspects of citizenship in lessons like history or social sciences

c) no explicit teaching of citizenship

\section{ASPECTS OF THE SCHOOL CULTURE TO BE ADDRESSED}

- collaboration between teachers - evidence of staff working as a team

- teacher participation in building a school community and extra-curricular activities

- involvement of parents - detection of tensions in teacher's and parents' expectations

- possible clash with "anti-school" norms of majority of students or important sub-groups of students

- the clarity of school regulations and collective norms (can the school head provide a written set of rules or norms, are they visibly displayed in the school?

- relational trust: the estimated degree of teacher-principal, teacher-teacher, student-teacher trust at school 


\section{CLASSROOM CLIMATE}

- general characteristics of teacher student relationships (authoritarian, strict, democratic, distant, supportive, respectful)

- the say that students have in school, classroom matters conflict handling in classes

- transparency in grading

- cooperative learning

- clarity on behavioural and disciplinary rules in classrooms

- dealing with diversity in classrooms (diversity in ability, levels, diversity in cultural background, grouping within classes, degree of individualizations, open discussion about differences in cultural background;teachers' sense of isolation

- the way students experience the classroom climate-various dimensions sense of belonging; psychological support

- sense of loneliness

- sub-cultures

- pleasure for breaking the rules

\section{E. SCHOOL LEADERSHIP}

- the way decisions are made at school (hierarchy, distributed leadership, staff acts as a collectivity, degree of discretion of the principal over staff, influence of the teaching staff; the experience of leadership as autocratic or democratic

\section{F. STRUCTURES FOR STUDENT INVOLVEMENT}

- listing structures of student involvement:

- school council

- school parliament

- choosing a class leader

- a school magazine (paper)

- preparing a play, exhibition, excursion

- student involvement in decision-making

- staff involvement in work concerning schools and extra-curricular activities, seen as a context for student involvement

\section{STUDENT'S INFORMAL LEARNING EXPERIENCES}

Critical incidents that involve:

- manifestation of aspect of school life (culture, classroom climate, leadership, student involvement);

- which creates a potential learning experience relevant to the development of active citizenship for students; 
- a potential that is made manifest on the basis of explicit reflections of teachers and students.

Note: the term "incident" need not be taken to the letter, in the sense of always being of short duration. Issues that evolve over long periods of time, and even projects could be included.

In principle, each element of the framework describing the school context could generate such critical incidents.

The way to elicit these critical incidents from interviews and focus groups could be, by referring to a particular element of lists C, D and E and ask: (e.g. for the first check-point of list C)

- Do you feel that the way the staff collaborates is sufficiently visible to the students to serve as a clear example?

- Would you say that staff collaboration is explicitly mentioned as a good example of collaboration at work/in society, in general?

- What learning experiences would students gain from this example?

To give a second example (second check-point of list $\mathrm{C}$ ):

- What image would you think students get from the degree of teacher participation in building a school community? Would you see this as a positive or a negative example, or is this an aspect that is largely invisible to the students?

The interviewers or leaders of the focus group sessions could also just mention each item from the list, and see whether it "rings a bell" to the respondents.

In the list of questions developed by the German team questions 73-80 ask about hypothetical situations, these could be used in addition.

Some further examples that have been obtained from the literature and from the exploratory case-studies:

a) the overall impression that students get from occasions in which they have protested against some official decision, from a teacher or the principal (see Rumanian exploratory case-studies);

b) what students learn from conflicts with teachers (see Rumanian exploratory case-studies);

c) the clash that is sometimes felt by expectations from parents/students and what teachers think they can feasibly realize (Italian exploratory case-studies), is this actually discussed and made explicit, also vis-à-vis students?

d) discussions about differences in cultural norms and principles like freedom of press and democracy, on the basis of the Danish cartoon incident;

e) the degree to which schools openly address controversial topics that are related to a multi-culturally heterogeneous school population;

f) whether schools address issues of social fairness when students should do a group assignment for which the group as a whole gets a mark;

g) can schools address the problem of anti-school group norms among sub-groups of students in a way that has pedagogical meaning?

h) the degree to which cooperative activities in preparing and performing a school play, exhibitions etc. are reflected upon and discussed; 
i) the degree to which school regulations and decision-making procedures are reflected upon from the perspective of general characteristics of democracy;

j) in the case of important political events like elections, are these discussed at school; are they made into a learning project?

k) a project in which the school rules and decisions-making processes are compared to the principles of democracy;

1) role playing to evoke confrontation with moral dilemmas;

m) a project in which the values in parts of the curriculum are made explicit;

n) incidents in which clashes between school norms and values and those of the home situation have to be dealt with;

o) dilemmas experienced in having clear disciplinary rules on the one hand (order) and wanting to stimulate student responsibility and autonomy on the other;

\section{References}

Abs, H. J., Breit, H., Huppert, A., Schmidt, A., \& Mueller-Mathis S. (2009). Germany. In: Scheerens, J. (ed.) Informal learning for active citizenship at school. Dordrecht/Heidelberg/London/New York: Springer.

Barzanò, G., Brumana, E., Musumeci, J. F., PastoreV., Palumbo, M., \& Razzi M. (2009). Italy. In: Scheerens, J. (ed.) Informal Learning for Active Citizenship at School. Dordrecht/Heidelberg/London/ New York: Springer.

Coombs, P. H., \& Ahmed, M. (1974). Attacking rural poverty. Baltimore: The Johns Hopkins University Press.

Council of Europe. (2004). Learning an living democracy. Council of Europe: All-European Study on Education for Democratic Citizenship Policies. Strassbourg.

Crick, D., Ruth, M. C., Monica Taylor, M., \& Ritchie, S. (2004). A systematic review of the impact of citizenship education on the provision of schooling. London: EPPI-Centre, Social Science Research Unit, Institute of Education.

Deal, T. E., \& Peterson, K. D. (1999). Shaping school culture. San Francisco: Jossey-Bass.

Diedrich, M. (2006). Connections between quality of school life and democracy in german schools. In A. Sliwka, M. Diedrich, \& M. Hofer (Eds.), Citizenship education. Münster: Waxmann Verlag.

Fordham, P. E. (1993). 'Informal, non-formal and formal education programmes' in YMCA George Williams College ICE301 Lifelong Learning Unit 2. London: YMCA George Williams College.

Halstead, J. M., \& Taylor, M. J. (2000). The development of values, attitudes and personal qualities: A review of recent research. Slough: National Foundation for Educational Research (NFER).

Hofstede, G. (1991). Cultures and organizations - Software of the mind. UK: McGraw-Hill Books.

Hoskins, B. (2006). Draft framework on indicators for active citizenship. Ispra: CRELL.

Hoskins, B., Villalba, E., Van Nijlen, D., \& Baden, C. (2008). Measuring civic competence in Europe. Ispra: CRELL.

Hendriks, M., \& Scheerens, J. (2009). The Netherlands. In: Scheerens, J. (ed.) Informal learning for active citizenship at school. Dordrecht/Heidelberg/London/New York: Springer.

Kennedy, K. J., Hahn, C. L., \& Lee, W.-O. (2008). Constructing Citizenship: Comparing the Views of Students in Australia, Hong Kong, and the United States. Comparative Education Review, 52, 53-92.

Maslowski, R., Breit, H, Eckensberger, L., \& Scheerens, J. (2009). A conceptual framework on informal learning of active citizenship competencies. In: Scheerens, J. (ed.) Informal learning for active citizenship at school. Dordrecht/Heidelberg/London/New York: Springer.

McMeekin, R. W. (2003). Networks of schools. Education Policy Archives, 11, 1-16.

Ministerie van Onderwijs, Cultuur en Wetenschap (2004). Citizenship: made in Europe: living together starts at school. The Hague: Ministerie van Onderwijs, Cultuur en Wetenschap.

Moos, L., Kresjer, J., \& Laursen, P. F. (2009). Denmark. In: Scheerens, J. (ed.) Informal learning for active citizenship at school. Dordrecht/Heidelberg/London/New York: Springer. 
OECD. (2007). Conceptual framework developed for the PISA governing board. Paris: OECD.

Pashiardis, P., Georgiou, M., and Georghiou, M. (2009). Cyprus. In: Scheerens, J. (ed.) Informal Learning for Active Citizenship at School. Dordrecht/Heidelberg/London/New York: Springer.

Paunescu, M., \& Alexandrescu, R. (2009). Rumania. In: Scheerens, J. (ed.) Informal learning for active citizenship at school. Dordrecht/Heidelberg/London/New York: Springer.

Scheerens, J. (ed.) (2009). Informal learning for active citizenship at school. Dordrecht/Heidelberg/ London/New York: Springer.

Schön, D. A. (1983). The reflective practitioner: How professionals think in action. New York: Basic Books.

Solvason, C. (2005). Integrating specialist school ethos....or do you mean culture? Education studies, 31, 85-95.

Szelényi, K., \& Rhoads, R. A. (2007). Citizenship in a global context: the perspectives of international graduate students in the United States. Comparative Education Review, 51, 25-47.

Taylor, M. (2002). School councils: Their role in citizenship and personal and social education. Slough: National Foundation for Educational Research (NFER).

Thomas, S. M., Peng, W. J., \& Yee, W. C. (2009). England. In: Scheerens, J. (ed.) Informal learning for active citizenship at school. Dordrecht/Heidelberg/London/New York: Springer.

Torney-Purta, J., Lehmann, R., Oswald, H., \& Schulz, W. (2001). Citizenship and education in twenty-eight countries: Civic knowledge at age fourteen. International Association for the Evaluation of Educational Achievement. 